\title{
A importância da frenectomia para o correto fechamento de diastemas
}

\section{The importance of frenectomy for the correct closing of diastemas}

\author{
Jeferson Luis de Oliveira Stroparo ${ }^{1,2}$, Geraldo Fernando Stroparo ${ }^{2}$, Sabrina Cunha da Fonseca ${ }^{3}$, \\ Juliane Maria Iagnes Prestes ${ }^{3}$, Gabriel Camargo de Oliveira ${ }^{1}$, Marilisa Carneiro Leão Gabardo ${ }^{1 *}$
}

\section{RESUMO}

O freio labial é um tecido conjuntivo composto por fibras de colágeno e fibras musculares, que tem como função impedir o excesso de exposição da mucosa e limitar os movimentos do lábio, ele tende a deslocarse apicalmente com o desenvolvimento. Em alguns casos este processo não ocorre, o que resulta em um posicionamento incorreto. Assim, o objetivo deste artigo é relatar o caso clínico de uma paciente de 13 anos de idade, do sexo feminino, com inserção anormal do freio labial, que dificultava o fechamento de um diastema durante o tratamento ortodôntico. A paciente foi submetida à cirurgia de frenectomia, onde $\mathrm{o}$ freio foi pinçado e o tecido excisado com o auxílio de uma lâmina de bisturi. Realizou-se fenestração periostal na área, que recebeu uma sutura com pontos simples em seguida. Após 45 dias, o freio labial se encontrava em uma nova posição, agora favorável ao fechamento ortodôntico do diastema. Concluiu-se que freio labial é uma estrutura anatômica que, quando incorretamente posicionada, tem repercussão no desfecho de outras especialidades odontológicas, como a Ortodontia, contudo, é essencial que o cirurgiãodentista conheça e domine técnicas de correção, como a frenectomia, que é de fácil execução, rápida e segura para o paciente.

Palavras-chave: Freio labial; Cirurgia oral; Diastema; Ortodontia.

\section{ABSTRACT}

The labial frenum is a connective tissue composed of collagen fibers and muscle fibers, whose function is to prevent excess exposure of the mucosa and limit the movements of the lip, it tends to move apically with development. In some cases this process does not occur, which results in an incorrect positioning. Thus, the objective of this article is to report the clinical case of a 13-year-old female patient with abnormal insertion of the labial frenum, which made it difficult to close a diastema during orthodontic treatment. The patient underwent frenectomy, where the frenulum was clamped and the tissue excised with the aid of a scalpel blade. Periosteal fenestration was performed in the area, which was then sutured with simple stitches. After 45 days, the labial frenum was in a new position, now favorable for orthodontic diastema closure. It was concluded that labial frenulum is an anatomical structure that, when incorrectly positioned, has repercussions on the outcome of other dental specialties, such as Orthodontics, however, it is essential that the dentist knows and controls correction techniques, such as frenectomy, which it is easy to perform, quick and safe for the patient.

Keywords: Labial Frenum; Oral surgery; Diastema; Orthodontics.

\footnotetext{
${ }^{1}$ Universidade Positivo, Escola de Ciências da Saúde - Curitiba - PR - Brasil.

*E-mail: marilisagabardo@gmail.com

${ }^{2}$ Consultório Privado - Irati - PR - Brasil.

${ }^{3}$ Universidade Federal do Paraná - Curitiba - PR - Brasil.
} 


\section{INTRODUÇÃO}

O freio labial é um tecido conjuntivo, elástico, composto por fibras de colágeno e musculares, definido como uma prega da membrana mucosa e de tecido fibroso de um lado; adere-se à superfície interna do lábio superior ligando essa à gengiva na linha mediana da maxila (BRAGA et al., 2007; OLIVI et al., 2018). Trata-se de uma região vascularizada e possui poucas ramificações nervosas periféricas delgadas, tendo como função impedir o excesso de exposição da mucosa e limitar os movimentos dos lábios, promovendo assim uma estabilização na linha média (BRAGA et al., 2007; OLIVI et al., 2018).

O posicionamento incorreto do freio labial pode gerar condições clínicas indesejáveis, tais como dificuldade no posicionamento da escova na altura do vestíbulo, retração de tecido no colo do dente, acúmulo de alimentos, restrição dos movimentos do lábio, interferência na fala e efeito estético indesejável (BRAGA et al., 2007; OLIVI et al., 2018). Devido às suas limitações foi criada uma classificação quanto à sua localização, dividindo os freios em dois grupos: o grupo das normalidades, que são catalogadas de acordo com suas características morfológicas, e o grupo das anormalidades, que contém os demais tipos dentro de variações morfológicas e funcionais (BRAGA et al., 2007; OLIVI et al., 2018).

Dentro das variações há o freio simples, o simples com apêndice e o simples com nódulo. Nas anormalidades há o freio bífido, o com recesso, o teto-labial persistente, o duplo e aqueles em que há coincidência de duas ou mais variações ou anormalidades (BRAGA et al., 2007; OLIVI et al., 2018). MIRKO et al. (1974) propuseram uma classificação dos freios labiais de acordo com o local de inserção, sendo divididos em: inserção na mucosa alveolar, incluindo a união mucogengival, gengiva inserida, papila interdental ou penetrante na papila.

Quando há necessidade de intervenção para sua correção, não existe na literatura um consenso quanto ao momento ideal; de forma geral, preconiza-se que a cirurgia ocorra após a erupção dos denyes caninos permanentes (MACEDO et al., 2012). Também há relato de indicação após a erupção dos incisivos laterais permanentes, com a sugestão de ser realizada a intervenção na dentição mista, caso haja a necessidade em 
razão de um freio labial hipertrófico que gere um diastema interincisal (MACEDO et al., 2012).

Mediante o exposto, o objetivo deste trabalho foi relatar um posicionamento anormal do freio labial que promoveu um diastema interincisivo, o qual foi tratado por meio de frenectomia para então ser dado prosseguimento ao tratamento ortodôntico.

\section{RELATO DE CASO}

Paciente de 13 anos, sexo feminino, compareceu ao consultório odontológico particular, acompanhada de um responsável. Durante a anamnese, o responsável relatou que a paciente foi encaminhada pelo especialista em Ortodontia para realização de uma frenectomia, pois a paciente possuía um freio com inserção muito baixa (Figura 1A), o que dificultaria o fechamento do diastema existente.

Durante o exame clínico, pode-se notar que a papila entre os dentes incisivos superiores ficava isquêmica quando o lábio era tracionado (Figura 1B). Além disso, foi observou-se que a inserção do freio se estendia até a porção palatina (Figura 1C e 1D), confirmando a necessidade de realização da cirurgia de frenectomia.

No momento da intervenção cirúrgica, os sinais vitais da paciente foram aferidos e se apresentaram estáveis e dentro dos padrões de normalidade. Foi realizada antissepsia extra e intrabucal bucal com digluconato de clorexidina $0,12 \%$. A anestesia se deu pela técnica infiltrativa em fundo de vestíbulo na região entre os incisivos centrais e laterais, com uso de um tubete anestésico de mepivacaína $2 \%$ com norepinefrina 1:100.000 (Mepiadre; DFL, Rio de Janeiro, RJ, Brasil).

O freio foi pinçado utilizando duas pinças hemostáticas curvas (Quinelato, Rio Claro, SP, Brasil) (Figura 1E) e então realizou-se a sua remoção completa até a porção palatina com uma lâmina de bisturi n. ${ }^{\circ} 15$ (Maxicor ${ }^{\circledR}$, Pinhais, PR, Brasil). Em seguida, foi feita a fenestração periosteal na área cirúrgica, pois essa técnica possibilita que durante a cicatrização o freio possa se restabelecer em uma inserção mais alta. Por fim, foram realizadas suturas simples (Figura $1 \mathrm{~F}$ ).

Figura 1 - Etapas do procedimento cirúrgico de frenectomia. A) Freio com inserção em gengiva inserida; B) Mucosa isquêmica quando o freio é tracionado; C) e D) Inserção do freio se estendendo até a porção palatina; E) Freio pinçado com duas pinças hemostáticas curvas; F) Remoção completa do freio até a porção palatina e sutura realizada. 

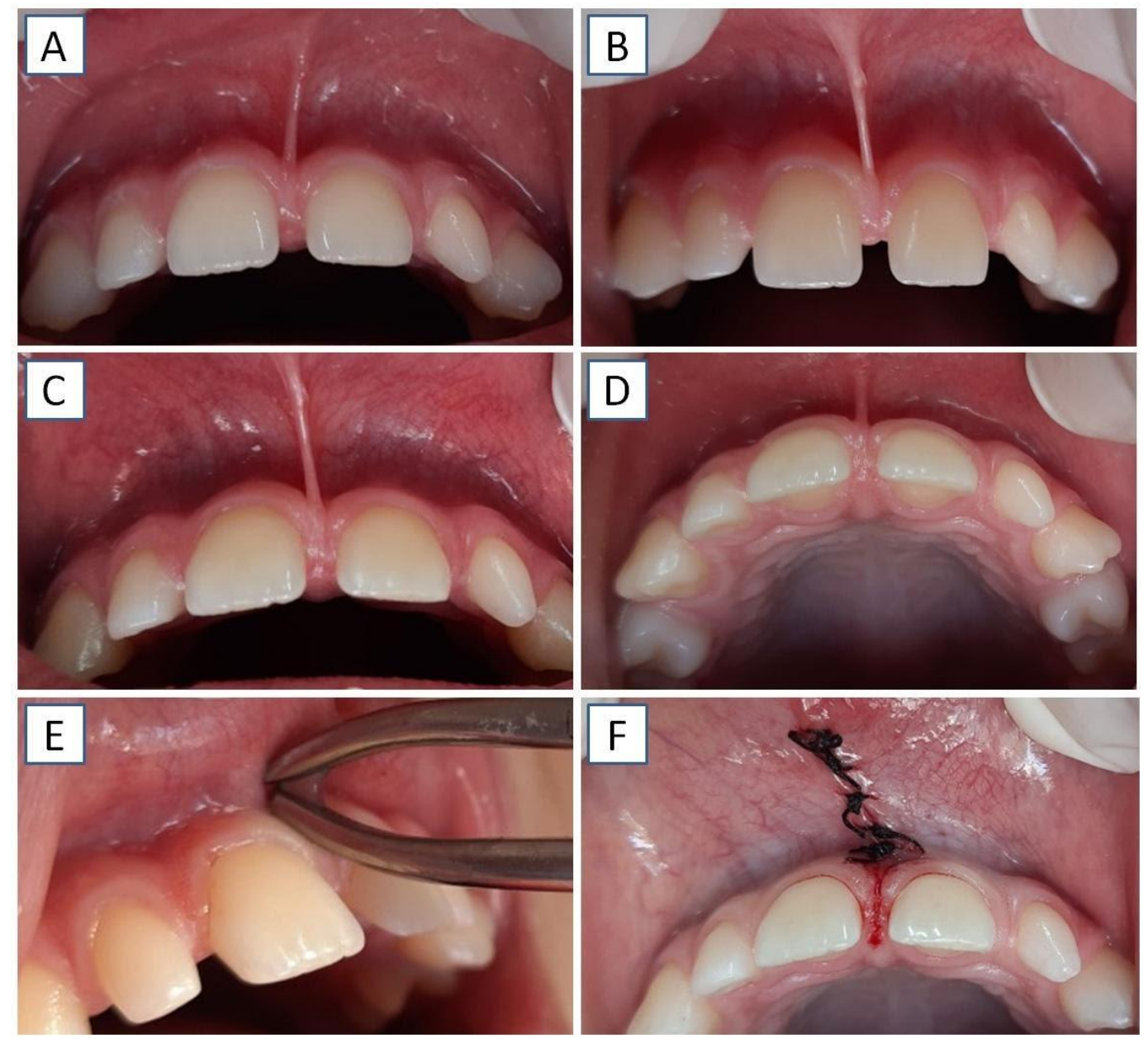

Fonte: Os autores (2022).

Foi prescrito Ibuprofeno $400 \mathrm{mg}$, uma cápsula a cada oito horas por três dias e a paciente foi acompanhada no pós-operatório. As suturas foram removidas 14 dias depois do procedimento. Após 45 dias, a paciente retornou para o acompanhamento e mostrou uma boa cicatrização, com inserção do freio em local adequado, possibilitando assim realizar o tratamento ortodôntico para fechamento do diastema. 
Figura 2 - Proservação do caso. A e B) Pós-operatório de 45 dias.
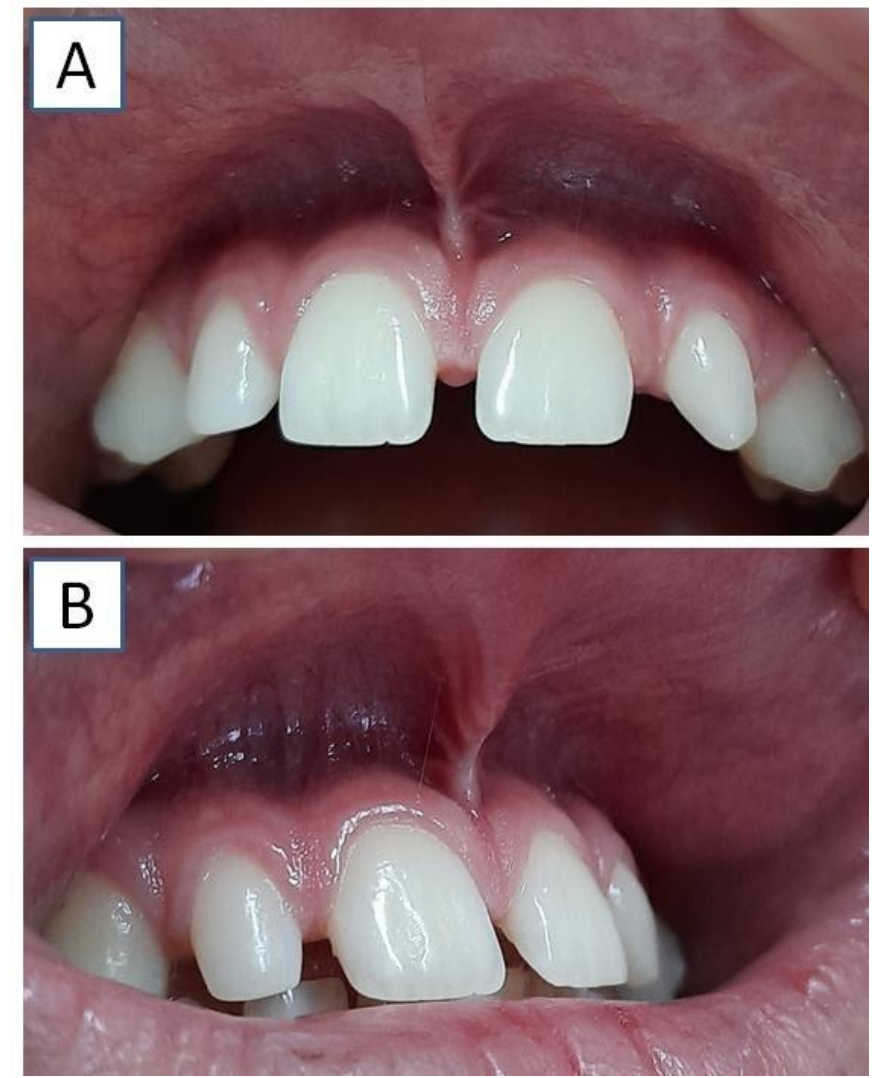

Fonte: Os autores (2022).

\section{DISCUSSÃO}

O freio labial é uma estrutura anatômica, formada por volta do terceiro mês de vida intrauterina, inicialmente apresenta-se inserido na papila palatina do recémnascido, atravessando todo o rebordo alveolar (SOUZA et al., 2017). Ao longo do crescimento e desenvolvimento da criança, sofre um deslocamento no sentido apical, até atingir uma posição acima da gengiva marginal (SOUZA et al., 2017).

Em alguns casos, podem ocorrer falhas neste processo, fazendo com que o freio tenha um posicionamento anormal e, como consequência, acaba gerando dificuldade de higienização, problemas fonéticos e estéticos (NUNES et al., 2021; SOUZA et al., 2017). Pode haver também a formação de recessões gengivais (STROPARO et al., 2021), bolsas periodontais, dificuldades no aleitamento materno, restrição dos movimentos labiais e também interferência no tratamento ortodôntico (NUNES et al., 2021; SOUZA et al., 2017), assim como descrito neste relato. 
O cirurgião-dentista, sob suspeita de posicionamento anormal do freio labial, deve realizar o tracionamento do lábio superior e observar se ocorre isquemia e deslocamento da papila palatina (SANTOS et al., 2014; SOUZA et al., 2017), procedimento executado durante a primeira consulta da paciente. Além disso, modelos de estudo podem ser utilizados como métodos auxiliares de diagnóstico, e as queixas estéticas, fonéticas e funcionais do paciente também devem ser consideradas e registradas (SANTOS et al., 2014; SOUZA et al., 2017).

Com a finalidade de corrigir este problema, abordagens cirúrgicas têm sido empregadas como tratamento de eleição para esses casos (CASTILLO et al., 2013). A cirurgia para correção dos diastemas interincisivos pode ser realizada antes, durante ou após o tratamento ortodôntico (SANTOS et al., 2014; SOUZA et al., 2017). Neste relato, ela foi realizada antes do tratamento, apresentando boa cicatrização.

Quanto à técnica, a frenectomia consiste na remoção completa do freio, sendo geralmente utilizada para freios hipertróficos, eliminando fibras transósseas que provocam tensão e costumam culminar no surgimento de diastemas interincisivos (TOLEDO, 2012). Na técnica convencional, uma lâmina de bisturi é utilizada na remoção do feio, podendo apresentar modificações de acordo com as características e finalidade da intervenção (PUIG et al., 1977; SOUZA et al., 2017).

Atualmente, novos métodos têm sido desenvolvidos com a proposta de otimizar os resultados deste tipo de procedimento, entre elas, a utilização do laser cirúrgico para frenectomia, sendo os modelos de $\mathrm{CO} 2$ e de diodo são os mais empregados, sendo que de forma geral, suas vantagens em relação aos métodos convencionais estão na capacidade de realizar um corte eficiente e preciso, além da facilidade de hemostasia transoperatória (NUNES et al., 2021).

Assim, cada tratamento deve ser cuidadosamente avaliado, sendo observada a morfologia do freio, as condições sistêmicas do paciente e as associações com outros tratamentos. Durante o tratamento ortodôntico, quando existe diastema interincisivo gerado pelo freio labial que não é removido, não há garantia de que o espaço se mantenha, uma vez que o tecido gengival não sofre reabsorção em um curto período de tempo como ocorre no tecido ósseo, então as fibras colágenas e elásticas são comprimidas e ocorre uma força de reação que acaba gerando recidiva do diastema (MACEDO et al., 2012), por este motivo e importância da intervenção com a cirurgia 
de frenectomia, para que se evite a recidiva do diastema e, por conseguinte, o fracasso do tratamento ortodôntico.

\section{CONCLUSÃO}

A técnica cirúrgica de frenectomia foi bem indicada para o caso aqui apresentado, com destaque para a importância de um diagnóstico preciso em que seja considerado o momento mais adequado para intervenção e, assim, haja sucesso no fechamento de diastemas causados pelo freio labial.

\section{REFERÊNCIAS}

BRAGA, A. T.; QUELEMES, P. V.; MOURA; W. L. D.; MOURA, W. L. D. Descrição da morfologia dos frênulos labiais superiores em escolares de Teresina. Revista de Cirurgia e Traumatologia Buco-Maxilo-Facial, v. 7, n. 3, p. 59-64, 2007.

CASTILlO, C. A. L.; BASUlTO, H. B.; SOCARRÁS, D. A.; PÉREZ, O. R.; GARCÍA, G. F. Frenillo labial superior doble. Revista Cubana de Pediatría, v. 85, n. 4, p. 523-528, 2013.

MACEDO, M. P.; CASTRO, B. S.; PENIDO, S. M. M. O.; PENIDO, C. V. S. R. Frenectomia labial superior em paciente portador de aparelho ortodôntico: relato de caso clínico. Revista Faculdade de Odontologia, v. 17, n. 3, p. 332-335, 2012.

MIRKO, P.; MIROSLAV, S.; LUBOR, M. Significance of the labial frenum attachment in periodontal disease in man. Part I. Classification and epidemiology of the labial frenum attachment. Journal of Periodontology, v. 45, n. 12, p. 891-894, 1974.

NUNES, J. E. P.; SILVA, A. L. DA.; NUNES, G. P.; FAGUNDES, C. F.; SOUZA, M. R. DE.; NAVARRO, R. S. Lasers applied to frenectomy in pediatric patients with ankyloglossia. Research, Society and Development, v. 10, n. 2, p. e19210210434, 2021.

OLIVI, M.; GENOVESE, M. D.; OLIVI, G. Laser labial frenectomy: a simplified and predictable technique retrospective clinical study. European Journal of Paediatric Dentistry, v. 19, n. 1, p. 56-60, 2019.

PUIG, J. R.; LEFEBVRE, E.; LANDAT, F. La technique de la plastie en Z, appliquée à l'hypertrophie du frein labial supérieur [Z-plasty technic, applied to hypertrophy of the upper labial frenum]. Journal of Stomatology, Oral and Maxillofacial Surgery, v. 78, n. 5, p. 351-356, 1977. 
SANTOS, P.; OSÓRIO, S. R. G.; FRANZIN, L. C. S. Diagnóstico e tratamento cirúrgico do freio labial anormal na dentição mista: relato de caso. Brazilian Journal of Surgery and Clinical Research, v. 8, n. 2, p. 41-46, 2014.

SOUZA, A.; SANTOS, A.; DALLÓ, F.; BEZ, L.; SIMÕES, P.; BEZ, L.; et al. Frenectomia labial maxilar: revisão bibliográfica e relato de caso. Revista de

Odontologia da Universidade Cidade de São Paulo, v. 27 n. 1, p. 82-90, 2017.

STROPARO, J. L. DE O.; WEISS, S. G.; STORRER, C. L. M.; DELIBERADOR, T. M. Application of an active oxygen (blue $\AA \mathrm{m}$ ) with free connective graft technique for root coverage - a case report. Research, Society and Development, v. 10, n. 5, p. e57510515468, 2021.

TOLEDO OA. Odontopediatria: fundamentos para a prática clínica. 4. ed. Rio de Janeiro: MedBook; 2012.

\section{Recebido em: 03/01/2022}

Aprovado em: 30/01/2022

Publicado em: 03/02/2022 